\title{
Promotion of cutaneous penetration of nifedipine for nanoemulsion
}

\author{
Paula de Oliveira Arantes ${ }^{1}$, Quesia Nery dos Santos ${ }^{1}$, Zaida Maria Faria de Freitas ${ }^{1}$, Alexandre \\ dos Santos Pyrrho ${ }^{2}$, Cristal Cerqueira-Coutinho ${ }^{3}$, Ana Lucia Vazquez Villa ${ }^{1}$, Elisabete Pereira dos \\ Santos ${ }^{1}$, Eduardo Ricci-Júnior, ${ }^{1, *}$
}

\begin{abstract}
${ }^{1}$ Faculty of Pharmacy, Galenic Development Laboratory (LADEG), Department of Medicine, Federal University of Rio de Janeiro, Rio de Janeiro, Brazil, ${ }^{2}$ Faculty of Pharmacy, Laboratory for Immunoparasitology and Toxicological Analysis, Department of Clinical and Toxicological Analysis, Federal University of Rio de Janeiro, Rio de Janeiro, Brazil, ${ }^{3}$ Technology Center, Institute of Macromolecules, Federal University of Rio de Janeiro, Rio de Janeiro, Brazil
\end{abstract}

\begin{abstract}
This article reports the development and characterization of a nanoemulsion (NE) able to improve the cutaneous penetration of nifedipine. NE with nifedipine was development and characterized, presenting droplet size of $20 \mathrm{~nm}$ with low polydispersity index (IP<0.1), spherical shape without aggregation, $\mathrm{pH}$ compatible with typical skin levels and stability evaluated by seven months. In the permeation studies, a classical formulation based in an oil/water cream containing nifedipine was used for comparison with NE. Nanoemulsion promoted and improved the retention of nifedipine in the epidermis and dermis in relation to classical formulation. This promoting effect is related to the nanometric size of the droplets of the NE $(20 \mathrm{~nm})$, which give him a large superficial area, favoring the contact of the nanocarrier with the skin surface. The NE was efficient in promoting accumulation of nifedipine in the dermis, which is the site of vasodilation action. NE was not irritating according to the primary dermal irritation tests. $\mathrm{NE}$ is a promising release system to promote cutaneous penetration of nifedipine and can be used in the future in clinical trials to promote healing of lesions caused by peripheral vascular diseases.
\end{abstract}

Uniterms: Topical nifedipine/cutaneous permeation. Nanoemulsion/characterization. Stability. Cutaneous permeation/study. Healing of wounds.

\section{INTRODUCTION}

Topical nifedipine is used for various purposes, such as treatment of periocular and face wrinkles (Innocenti et al., 2010; Calabro et al., 2014), closure of anal fissures (Golfam et al., 2010; Katsinelos et al., 2006), and particularly to promote healing of skin wounds (Smith 2010; Melo et al., 2008; Ebadi et al., 2003). Nifedipine (NFD) is a calcium channel blocker and its use was first recommended for treatment of cardiovascular diseases. Topical administration of nifedipine is advantageous to avoid the systemic effects of oral administration. For wound treatment, topical nifedipine has been employed to treat lesions caused by peripheral vascular disease and diabetes (Tosiello, Kopacki, 2000) as well as bedsores (Melo et al., 2008). Clinical studies have been published

\footnotetext{
* Correspondence: E. Ricci-Júnior. Faculdade de Farmácia. Universidade Federal do Rio de Janeiro. Av. Carlos Chagas Filho, Ilha do Fundão - 21941-590 - Rio de Janeiro - RJ, Brazil. E-mail: ricci@pharma.ufrj.br
}

on the topical use of nifedipine to promote wound healing (Smith 2010; Tosiello, Kopacki, 2000). In the development of formulations for topical use, permeation studies are necessary to assess the drug's safety and cutaneous retention.

One of the main functions of the skin is to protect the organism from dehydration and harm from the environment. It is formed by the epidermis, dermis and hypodermis. The epidermis is the outer skin layer. The top part of the epidermis is the stratum corneum (SC), composed of unviable keratinized cells called corneocytes. These cells are surrounded by a lipid bilayer and joined by a complex lipid matrix. Therefore, the SC acts as a barrier that can control the permeation of drugs through the skin (Williams, 2003; Schaefer, Redelmeier, 1996). Drugs formulations for topical use must have high penetration in the SC, bioaccumulation in the viable epidermis and dermis and low or no systemic absorption, to avoid adverse side effects. The dermis is the action site of vasodilatory drugs as nifedipine. The great challenge of cutaneous 
release is to overcome the barrier effect of the SC. For this purpose, several release systems have been studied, such as nanoparticles, liposomes, microemulsions (Neubert, 2011) and nanoemulsions (Kong et al., 2011), to promote cutaneous penetration of drugs.

Nanoemulsions (NEs) have been widely used in the pharmaceutical area as carriers of hydrophobic drugs. The majority of NEs are dispersions of oil droplets in water with diameter below $100 \mathrm{~nm}$. The main advantages of these nanocarriers are ease of preparation, possibility of industrial-scale production and high thermodynamic stability (Campos, Ricci-Junior, Mansur, 2012; Trommer, Neubert, 2006). NE can promote cutaneous permeation of drugs. Their nanometric droplets have large surface area, facilitating the contact of the nanocarrier with the skin (Kong et al., 2011)], and consequently favoring cutaneous permeation of drugs. The surfactants included in the NEs can promote reduction of the surface tension between the droplets and skin, improving the spreadability, contact and bioadhesion of the formulation. The droplets can act as a reservoir system for sustained drug release (Trommer, Neubert, 2006).

This article reports the preparation and characterization of a nanoemulsion (NE) for promoting the penetration and cutaneous retention of nifedipine. NE was produced and characterized by size distribution, $\mathrm{pH}$, concentration, morphology by transmission electron microscopy (TEM), viscosity, stability during 7 months, and studies of permeation and retention using pig skin. Primary and cumulative skin irritability tests were available using rabbits.

\section{MATERIAL AND METHODS}

\section{Material}

Nifedipine was purchased from Pharmanostra (Brazil); Tween 20® was acquired from Tédia (Brazil); Pluronic F127® was purchased from Sigma Aldrich (USA); peppermint essential oil was acquired from Ferquima (Brazil); and Transcutol $\mathrm{P} 囚$ was purchased from Brasquim (Brazil). All chemicals or solvents used were of analytical or pharmaceutical grade and all reagents were used as received.

\section{Preparation of the formulations}

\section{Nanoemulsion}

The oil-in-water $(\mathrm{O} / \mathrm{W})$ nanoemulsion $(\mathrm{NE})$ was prepared by high-energy method (Figure 1) using an ultrasound processor (Hielscher model UP100H), according to a method adapted from literature (Senna, Ricci-Júnior, Mansur, 2015). The components and processing conditions are reported in Table I. Initially, $0.33 \mathrm{~g}$ of nifedipine was dissolved in $1 \mathrm{~g}$ of Transcutol ${ }^{\circledR}$ yielding $1.33 \mathrm{~g}$ of drug solution. Ten grams $(10 \mathrm{~g})$ of oily phase were obtained by adding the solution of nifedipine in $8.67 \mathrm{~g}$ of peppermint essential oil. Ninety grams ( $90 \mathrm{~g})$ of aqueous phase were prepared by adding $9 \mathrm{~g}$ of Pluronic F127® and $4.5 \mathrm{~g}$ of Tween $20 \AA$ in $76.5 \mathrm{~g}$ of water. Then $10 \mathrm{~g}$ of oil phase were added to $90 \mathrm{~g}$ of aqueous phase under constant ultrasound homogenization (amplitude $40 \%$ ) during $5 \mathrm{~min}$ in an ice bath at $5{ }^{\circ} \mathrm{C}$ to prevent heating of the formulation. This method was used to prepare NE (Table I).

\section{Cream O/A}

A commercial formulation containing $0.33 \%$ of nifedipine was used for comparative purposes with the nanoemulsion. The formulation was prepared in the compounding pharmacy from Federal University of Rio de Janeiro (UFRJ).

The components are reported in Table II. Components 1 to 9 of the table were weighed and mixed to produce the oil phase. The aqueous phase (component 10) and oil phase (components 1 to 9 ) were heated separately to 80 and $75^{\circ} \mathrm{C}$, respectively. The aqueous phase was added to the oil phase slowly under constant agitation using a mechanical screw mixer at room temperature $\left(25^{\circ} \mathrm{C}\right)$. The cream was stored at room temperature protected from direct light.

\section{Characterization of the formulations}

\section{Nanoemulsions}

Besides size distribution and polydispersity index, the nanoemulsion was also characterized in relation to organoleptic characteristics, $\mathrm{pH}$, morphology by Transmission Electron Microscopy, viscosity, content and concentration.

With respect to the organoleptic characteristics, NE was observed for formation of crystals, both to the naked eye and under a Quimis optical microscope at 100 $\mathrm{x}$ magnification. The formation of crystals can indicate physical-chemical instability and the need to adjust the composition. The parameters evaluated were aspect, color, transparency and crystal formation.

The $\mathrm{pH}$ was measured with a potentiometer (Bante Instrument, model 922) that had been previously calibrated with standard buffer solutions having $\mathrm{pH} 4.0$ and 7.0. The device's electrode was immersed in the sample and the $\mathrm{pH}$ values were read in triplicate at temperature of $25^{\circ} \mathrm{C}$. 


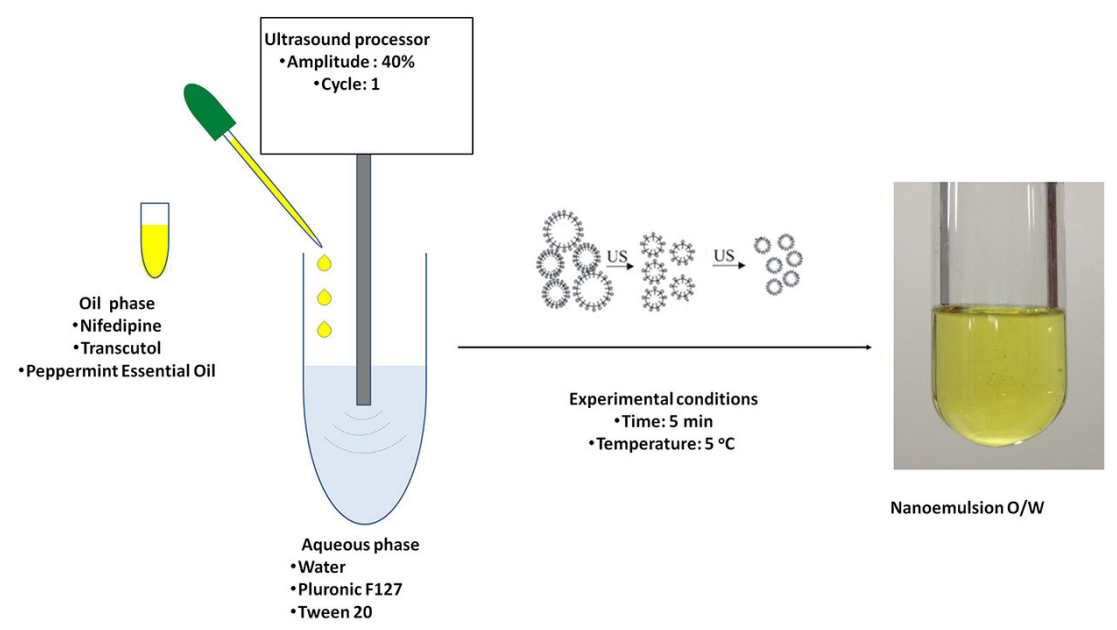

FIGURE 1 - Preparation of nanoemulsion by high-energy method.

TABLE I - Components and experimental condition

\begin{tabular}{lcccccccc}
\hline $\mathbf{F}$ & \multicolumn{3}{c}{ OPH } & \multicolumn{3}{c}{ APH } & & \\
\cline { 2 - 8 } & $\mathrm{NFD} \% \mathrm{w} / \mathrm{w}$ & $\mathrm{TC} \% \mathrm{w} / \mathrm{w}$ & $\mathrm{PEO} \% \mathrm{w} / \mathrm{w}$ & $\mathrm{P} \% \mathrm{w} / \mathrm{w}$ & $\mathrm{TW} \% \mathrm{w} / \mathrm{w}$ & $\mathrm{W} \% \mathrm{w} / \mathrm{w}$ & $\mathrm{A}(\%)$ & $\mathrm{T}(\mathrm{min})$ \\
\hline $\mathrm{NE}$ & 0.33 & 1 & 8.67 & 9 & 4.5 & 76.5 & 100 & 5 \\
\hline
\end{tabular}

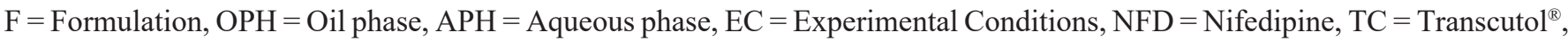
$\mathrm{PEO}=$ Peppermint Essential Oil, $\mathrm{P}=$ Pluronic $^{\circledR} \mathrm{F} 127, \mathrm{TW}=$ Tween $20^{\circledR}, \mathrm{W}=$ water, $\mathrm{A}(\%)=$ amplitude in percentage $(\%), \mathrm{t}=$ time in minutes, $\mathrm{NE}=$ Nanoemulsion, $\% \mathrm{w} / \mathrm{w}=$ Percentage Weight for Weight

TABLE II - Components and preparation technique of the cream

\begin{tabular}{lc}
\hline Components & Quantity (g) \\
\hline (1) Ethoxylated cetostearyl alcohol & 2.5 \\
(2) Solid petroleum jelly & 2.0 \\
(3) Isoctyl stearate & 3.0 \\
(4) Propylene glycol & 5.0 \\
(5) Methylparaben & 0.1 \\
(5) Glyceryl monostearate & 5.0 \\
(6) Cetostearyl alcohol & 2.0 \\
(7) Propylparaben & 0.1 \\
(8) Nifedipine & 0.3 \\
(9) Transcutol & 10.0 \\
(10) Distilled water & Sqc 100 \\
\hline
\end{tabular}

sqc $=$ sufficient quantity to complete

The morphology of the nanoemulsions was analyzed by transmission electron microscopy (TEM) with an FEI Morgagni $^{\mathrm{TM}} 268$ microscope. The sample was diluted in water at $1: 1$ and then $5 \mu \mathrm{L}$ of diluted nanoemulsion was added through a copper grid (300 mesh) with carbon and Formvar (polymer film) coating. The excess was removed with filter paper and the residual water was removed by placing the samples in a vacuum desiccator, for subsequent observation under the electron microscope.

The droplet size distribution and PDI were measured using a Malvern NanoSizer ${ }^{\circledR}$ model $90 \mathrm{~S}$ (UK). The samples were diluted in distilled water at 1:10 and analyzed in a quartz cell with $1 \mathrm{~cm}$ optical path at room temperature. The analyses were carried out in triplicate.

The viscosity was measured using an AR 2000 advanced rheometer (TA Instruments) using cone-plate geometry, angle of $1^{\circ}$ and $60 \mathrm{~mm}$ diameter. The viscosity was measured in continuous mode, applying a shear rate in the range from 0.01 to $500 \mathrm{~s}^{-1}$ at $37^{\circ} \mathrm{C}$ to simulate the body temperature. The thixotropy was determined using strains of 10 and $100 \mathrm{~s}^{-1}$ by 20 minutes.

The nifedipine concentration in the NE was determined by high-performance liquid chromatography (HPLC) at 0, 7, 30, 90 and 210 days. Nanoemulsion was diluted with the mobile phase, filtered (syringe filter, hydrophilic membrane, pore size of $0.45 \mu \mathrm{m}$ ) and analyzed by HPLC. The analyses were performed in triplicate.

\section{Cream $O / A$}

The cream was characterized to determine the droplet size distribution and morphology by optical microscopy. The cream was diluted in distilled water at 
1:1 and oily droplets were placed on slides for observation under a Leica DMLS microscope. Images were obtained with a Moticam 1000 digital camera and processed with the Motic Imagem Plus 2.0 software.

The average droplet diameter was determined with a Malvern Scirocco ${ }^{\circledR} 2000$ Mastersizer particle size analyzer and the data were processed with the Mastersizer 2000 software (version 5.60).

The cream was diluted in distilled water at 1:500 and the studies were performed in triplicate. The cream was diluted 1: 100 with distilled water and the $\mathrm{pH}$ was measured using a $\mathrm{pH}$ meter $(\mathrm{pH}$ Meter Cherker portable, Hanna, Woonsocket, RI, USA). The mean \pm SD of $n=6$ determinations was evaluated.

\section{Stability}

To study the nanoemulsions' stability, their size distribution and polydispersity index were measured, using the dynamic light scattering (DLS) method with a Malvern model 90S NanoSizer® (UK). The samples were diluted in distilled water at 1:10 and analyzed in a quartz cell with $1 \mathrm{~cm}$ optical path at room temperature. These analyses were conducted in three runs with 15 readings. The values shown are the mean \pm standard deviation of three measurements for each formulation. The polydispersity index (PDI), calculated by the device reflects the homogeneity profile of the sample's droplet diameter. PDI results lower than 0.20 were considered satisfactory (Zetasizer Nano, 2004). The size distribution and PDI measurements were obtained at room temperature $\left(25^{\circ} \mathrm{C}\right)$ immediately after processing and (0 day) at intervals of 7, 21, 30, 60, 90, 150, 180 and 210 days afterward. During the study, NE was kept in hermetically sealed amber glass flasks at room temperature $\left(25^{\circ} \mathrm{C}\right)$.

\section{In vitro permeation study}

In vitro permeation studies try to mimic the test drug's permeation through human skin layers, by using chromatography to quantify the drug present in the epidermis, dermis and receptor solution. For this purpose, samples of pig ear skin were obtained from animals about three months old. The skin samples were cut with scissors and carefully examined for the presence of any wounds, punctures, bleeding or skin disease. The samples were then cleaned in distilled water and sectioned with scissors and scalpel. During the cleaning process, the integrity of the skin was verified. Skins with cuts or holes on the surface were discarded. Furthermore, during the permeation studies, we did not observe the occurrence of "burst effect". This fact is not tolerated and the experiment is discarded. Thus, we guarantee the veracity of the results of the permeation study.

The permeation was measured with a Franz vertical cell diffusion system, composed of a donor compartment with diffusion area of $1.54 \mathrm{~cm}^{2}$ and receptor compartment with volume of $7.5 \mathrm{~mL}$. The pig skin sample was placed over the cell with the epidermis facing the donor compartment. The receptor medium used was phosphate-buffered saline ( $\mathrm{pH} 7.4$ ) containing $0.2 \%$ sodium dodecyl sulfate (SDS), kept under constant agitation with a magnetic stirrer, in a water bath heated to $32{ }^{\circ} \mathrm{C}$. The receptor medium contains tensoactive (SDS) to maintain sink conditions ensuring the nifedipine solubility. The nifedipine solubility in the receptor solution was $350 \mu \mathrm{g} / \mathrm{mL}$. A nanoemulsion sample of $600 \mathrm{mg}$ was applied on each cell and the system was closed. A sample of $200 \mathrm{~mL}$ of the receptor medium was collected for analysis after 1,2, 3 and $4 \mathrm{~h}$. At the end of the experiment, the skin segments were removed and cleaned with cotton moistened with distilled water followed by drying with cotton. To quantify the nifedipine retained in the skin layers, the epidermis and dermis were separated with a scalpel, according to the method standardized by our group (Monteiro et al., 2012). The epidermis and dermis samples were cut into small pieces with scissors and transferred to amber test tubes, to which $1 \mathrm{ml}$ of mobile phase was added. The tubes containing the epidermis or dermis samples were then vortexed three times for 60 seconds each. The resulting material from each tube was filtered (membrane with pore size of $0.45 \mu \mathrm{m}$ ) and analyzed by HPLC. Six replications were performed for the formulation and the results are the mean and standard deviation of six measurements.

\section{HPLC}

The nifedipine was identified and quantified by HPLC with a Gilson chromatograph and Sigma-Aldrich Kromasil ${ }^{\circledR}$ C 18 column (dimensions $250 \times 4.6$ mm; $5 \mu \mathrm{m}$ ), mobile phase of methanol:acetonitrile:water in 35:35:30 proportion, flow of $1.5 \mathrm{~mL} / \mathrm{min}$, ultraviolet detector (UV) with detection wavelength $(\lambda)$ of $235 \mathrm{~nm}$, temperature of $40{ }^{\circ} \mathrm{C}$ and injection volume of $25 \mu \mathrm{L}$.

Linearity was determined by the construction of three analytical curves. Nifedipine was dissolved in methanol to obtain the concentration of $500 \mu \mathrm{g} / \mathrm{mL}$. The stock solution was diluted in the mobile phase in the concentrations of $2.5,5,10,20,30$ and $50 \mu \mathrm{g} / \mathrm{mL}$. The samples were filtered (membrane with pore size of 0.45 $\mu \mathrm{m})$ and analyzed by HPLC. Linear regression analysis was applied in the results to calculate the calibration equation and the determination coefficient $\left(\mathrm{R}^{2}\right)$. 
The selectivity was assessed by adding $0.3 \mathrm{~g}$ of porcine skin (area $1.54 \mathrm{~cm}^{2}$ ) in $1 \mathrm{~mL}$ of mobile phase in a test tube for 2 hours. Formulations (NE and cream) without nifedipine were diluted in mobile phase in a test tube for 2 hours. Subsequently, the solutions obtained with skin extract and formulations on mobile phase were filtered (membrane with pore size of $0.45 \mu \mathrm{m}$ ) and analyzed by HPLC.

Precision is the assessment of the closeness of the results obtained in a series of measurements of a multiple sampling of the same sample (ANVISA, 2003). Three levels $(5,10$ and $20 \mu \mathrm{g})$ were added to skin samples according to the method described above. In the intra-day assays, three concentrations were analyzed, low, medium and high in sextuplicate $(5,10$ and $20 \mu \mathrm{g} / \mathrm{mL})$ and the samples were analyzed in the same day. In the inter-day assay, the samples $(5,10$ and $20 \mu \mathrm{g} / \mathrm{mL})$ were analyzed in sextuplicate in two days. The intra-day and inter-day precision were determined from the relative standard deviation (RSD) according to the equation (1) (ANVISA, 2003):

$$
\mathrm{RSD}=(\mathrm{SD} / \mathrm{M}) \times 100 \quad \text { Equation }(1)
$$

where RSD is relative standard deviation, SD is standard deviation and $\mathrm{M}$ is mean area.

Accuracy was attained via the recovery assay, in which known quantities of nifedipine standard were added to a known quantity of the skin sample (weight average $0.3 \mathrm{~g}$ and area $1,54 \mathrm{~cm}^{2}$ ). The accuracy of the method was evaluated in triplicate at three concentration level, and the percentage recoveries were calculated. Skin samples of $0.3 \mathrm{~g}$ (area of $1.54 \mathrm{~cm}^{2}$ ) were cut into small pieces using a scissor. To validate the recovering method of nifedipine from the skin sample, three quantities of nifedipine in methanol (drug mass referring to 5, 10, and $20 \mu \mathrm{g}$ ) were added in skin samples in triplicate. After evaporation of the solvent (methanol), $1 \mathrm{~mL}$ of the mobile phase was added to each tube, which was mixed for 60 seconds three times. The samples were filtered (membrane with pore size of $0.45 \mu \mathrm{m}$ ) and analyzed by HPLC. The recovery process was carried out in triplicate. The data were presented in percentage of recovered drug from the three levels.

\section{In vivo study of primary skin irritation by modified Draize method}

The primary irritation level was determined to estimate the toxicity of the formulation to mammal skin (Gad, McCord, 2008; Draize, Geoffrey, Herbert, 1944). The animal experiments were performed in accordance with the code of ethics of the Committee on Ethical Use of Animals (CEUA) of Rio de Janeiro
Federal University (UFRJ), under the following permits: FARMACIA012-08/16 for primary skin irritability. The mammal chosen was the albino rabbit weighting around $2.0 \mathrm{~kg}$ for testing each formulation (New Zealand lineage), because its skin is more sensitive than human skin. The rabbits were kept in individual cages at room temperature $\left(25^{\circ} \mathrm{C}\right)$. Animals with skin injuries were excluded from the test.

For the primary irritability tests, the backs of the six rabbits were shaved 24 hours before applying the formulation. Four areas were chosen at random on the back of each rabbit for application, two of which were abraded and two without abrasion. Before the test started, skin cutaneous thickness of the trichotomized areas were measured using a caliper serving as a reference to determine if an edema was formed at the end of the test.

Five hundred milligrams of NE was applied and the site was covered with a bandage (gauzes) for 4 hours. After 4 hours the gauzes were removed from both sides and the product was removed using distilled water. The final evaluations were performed 24 and 72 hours using the caliper. Edema formation was assessed subtracting the initial thickness value from the final value (for 24 or 72 hours) and dividing by two.

The formation of edema was performed using Equation 2.

$$
E D(m m)=\frac{L t-L i}{2} \quad \text { Equation } 2
$$

where $\mathrm{ED}(\mathrm{mm})$ is a measure of the increased thickness of the skin in millimeters, $\mathrm{Li}$ is the initial measurement made with caliper, and Lt is measured in an established times.

Formulation was classified according to the edema thickness: 0 to $0.24 \mathrm{~mm}$ corresponding to no-edema (score grade 0$) ; 0.25$ to $0.49 \mathrm{~mm}$ corresponding to very slight edema (score grade 1 ); 0.5 to $0.74 \mathrm{~mm}$ corresponding to slight edema (score grade 2);0.75 to $1.00 \mathrm{~mm}$ corresponding to moderate edema (score grade 3 ) and $>1.00 \mathrm{~mm}$ corresponding to severe edema (score grade 4) (Draize, Geoffrey, Herbert, 1944).

The possibility of erythema formation was evaluated e classified according to the skin characteristics: white to pink corresponding to no-erythema (score grade 0 ); light red corresponding to very slight erythema (score grade 1); red corresponding to slight erythema (score grade 2); very red corresponding to moderate erythema (score grade 3) and dark red with eschar formation corresponding to severe erythema (score grade 4) (Draize, Geoffrey, Herbert, 1944). 
Primary skin irritation was assessed from the mean grade values (edema and erythema) in 24 and 72 hours. Primary cutaneous irritation index was assessed by dividing by two the sum of the mean grade values (edema plus erythema) obtained for 24 and 72 hours (Draize, Geoffrey, Herbert, 1944). The results of the primary cutaneous irritation index can be classified according to the range: 0 to 0.9 corresponding to non-irritating; 1 to 1.9 corresponding to slightly irritating; 2.0 to 4.9 corresponding moderately irritating and 5.0 to 8.0 corresponding to severely irritating (Draize, Geoffrey, Herbert, 1944).

\section{Statistical analysis}

The data from comparing the groups were submitted to analysis of variance (ANOVA) and the Tukey test, at significance of $95 \%$ ( $p$-value $<0.05$ considered significant) using the Origin ${ }^{\circledR}$ software (version 8.0), the same program used to calculate the means and standard deviations.

\section{RESULTS AND DISCUSSION}

The stability results, based on the droplet size distribution and polydispersity index (PDI), are reported in Table III. NE was prepared using a high-energy method. This method was chosen because it is practical, easy and suitable for preparing of NE in laboratory scale. The ultrasound waves cause dispersion of the oil phase in the aqueous phase and produce nanometric droplets. The oil phase/aqueous phase proportion was kept constant. The $10 \% \mathrm{w} / \mathrm{w}$ proportion was the maximum oil phase amount that could be incorporated in the aqueous phase without impairing the nanoemulsions' stability, because higher proportions caused an increase in the droplet diameter and polydispersity index. The aqueous phase contains tensoactives. Pluronic F127 $®$ and Tween $20 \AA$ act synergistically as tensoactives stabilizing the NE. The combination promotes the stability of the dispersed system by forming a film covering the oil droplets of the NE. The oil phase contained peppermint essential oil and Transcutol $P \AA$, which was used to dissolve the drug before addition in the essential oil. The essential oil was obtained commercially (Ferquima, Brazil) and its main component is menthol (40-55\%). It is readily available and has low toxicity, low cost, and a pleasant smell. Therefore, it can be used safely in formulations for external application at concentrations ranging from 5 to 20\% (Herbal Medicine, 2000).

Figure 2 contain the size distribution graph of the NE. It was produced and analyzed for stability by determining the droplet size distribution and polydispersity index (PDI) (Table III). These two parameters have been used to assess the stability of nanoemulsions (Senna, Ricci-Júnior, Mansur, 2015). NE remained stable, with size below $24 \mathrm{~nm}$ and PDI lower than 0.20 after 210 days.

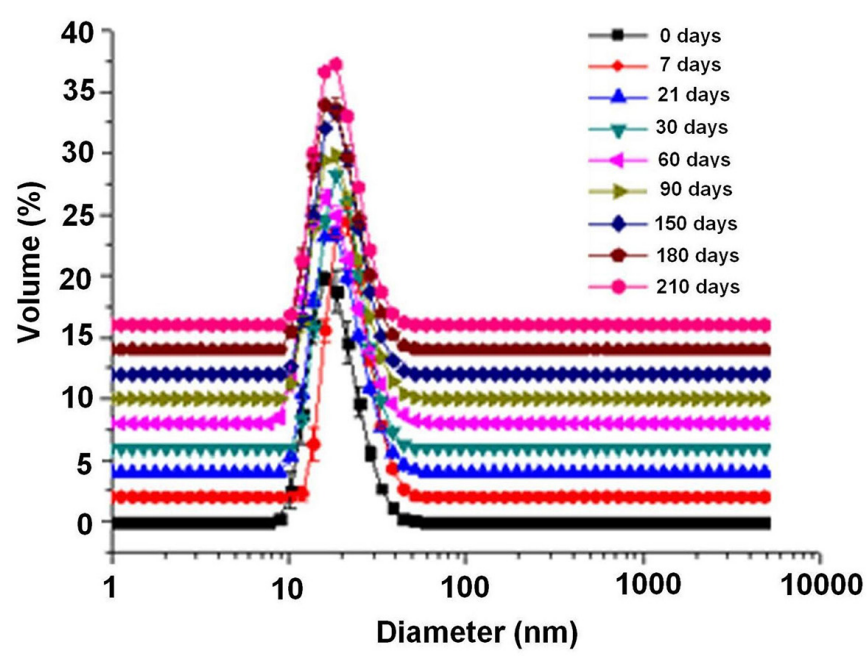

FIGURE 2 - Droplet size distribution profile of the nanoemulsion obtained during the stability study $(0,7,21,30,60,90,150,180$ and 210 days).

The transmission electron microscopic images revealed the morphology of the droplets, which were spherical and separated (Figure 3). The images show individual spherical droplets containing nifedipine with nanometric dimensions (Figure 3A). Figure 3B shows expanded images of the NE droplets.

With respect to the organoleptic characteristics, NE presented light yellow color, translucent, characteristic smell and absence of crystals. Table IV presents the results of the $\mathrm{pH}$, concentration, content, size distribution, and polydispersity index of NE. The $\mathrm{pH}$ values found are near those of human skin, of about 5.5. Therefore, the $\mathrm{pH}$ of the formulation was compatible with the physiological $\mathrm{pH}$ (Table IV). Nifedipine is practically insoluble in the water $(0.005 \mathrm{mg} / \mathrm{mL})$ (Ali, 1989). Drug solubility in the oil phase was $33 \mathrm{mg} / \mathrm{mL}$ (Table I). Thus, nifedipine concentration and content were $3.3 \mathrm{mg} / \mathrm{ml}$ and $0.33 \% \mathrm{w} / \mathrm{w}$ (Table IV), respectively. The formulation was stored at room temperature $\left(25^{\circ} \mathrm{C}\right)$ and protected from light. The drug content in the formulation was measured at $0,7,30,90$ and 210 days. The drug content in the formulation was reduced from 0.33 to $0.32 \% \mathrm{w} / \mathrm{w}$ in 210 days. The reduction in the concentration was small and the formulation can be considered stable.

NE presented low viscosity, which is adequate for topical products of cutaneous administration in wounds, 
TABLE III - Stability data of the nanoemulsion (NE)

\begin{tabular}{|c|c|c|c|c|c|c|}
\hline & $\mathbf{0 d}$ & & $7 \mathrm{~d}$ & & $21 \mathrm{~d}$ & \\
\hline $\mathbf{F}$ & Size $(\mathrm{nm})$ & PDI & Size (nm) & PDI & Size $(\mathrm{nm})$ & PDI \\
\hline \multirow[t]{2}{*}{ NE } & $18.84 \pm 0.13$ & 0.08 & $21.30 \pm 0.06$ & 0.04 & $19.88 \pm 0.14$ & 0.09 \\
\hline & $30 \mathrm{~d}$ & & $60 \mathrm{~d}$ & & $90 \mathrm{~d}$ & \\
\hline $\mathbf{F}$ & Size (nm) & PDI & Size (nm) & PDI & Size $(\mathrm{nm})$ & PDI \\
\hline \multirow[t]{2}{*}{ NE } & $19.80 \pm 0.10$ & 0.05 & $20.76 \pm 0.50$ & 0.10 & $19.52 \pm 0.03$ & 0.08 \\
\hline & $150 \mathrm{~d}$ & & $180 \mathrm{~d}$ & & $210 d$ & \\
\hline $\mathbf{F}$ & Size (nm) & PDI & Size (nm) & PI & Size $(\mathrm{nm})$ & PI \\
\hline NE & $20.34 \pm 0.11$ & 0.07 & $19.06 \pm 0.02$ & 0.07 & $21.81 \pm 0.83$ & 0.08 \\
\hline
\end{tabular}

The size values are mean \pm standard deviation of $n=3$ measurements. The PDI values are the mean of $n=3$ measurements. PDI values lower than 0.2 were considered satisfactory according to the Zetasizer Nano manual (2004).
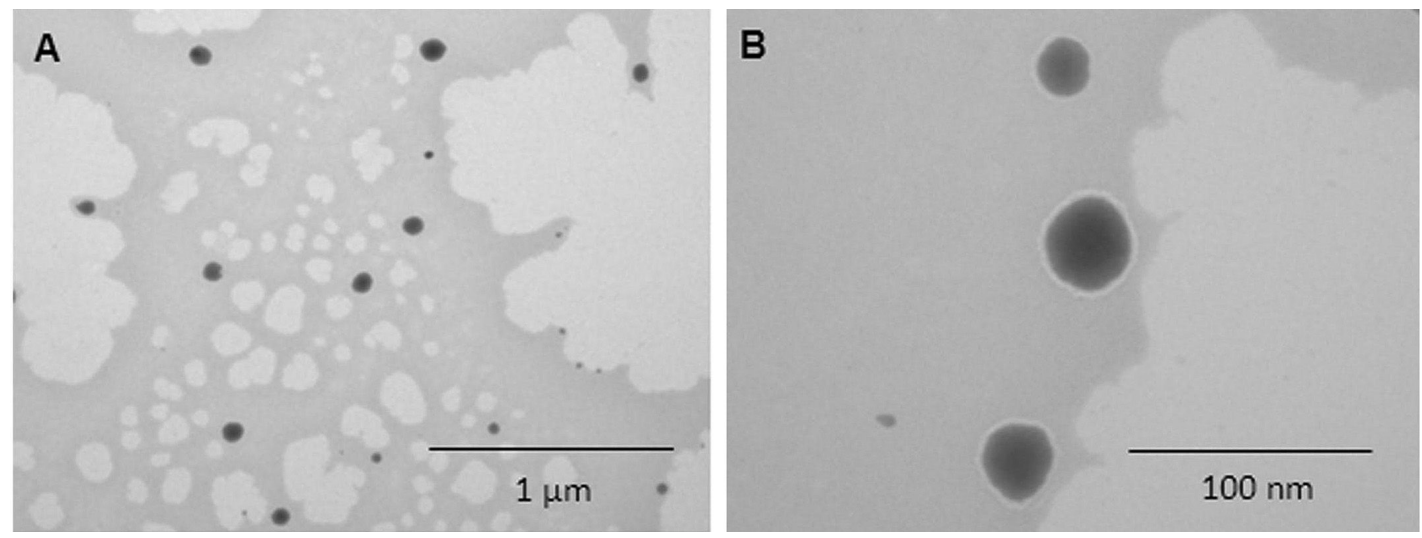

FIGURE 3 - Transmission electron photomicrograph of nanoemulsion containing nifedipine: A) panoramic and B) expanded.

TABLE IV - Results of the organoleptic characteristics, $\mathrm{pH}$, content, size distribution, and polydispersity

\begin{tabular}{lc}
\hline Characterization & NE \\
\hline $\mathrm{pH}$ & $5.83 \pm 0.01$ \\
Content (\%) (0 d) & $0.33 \pm 0.009$ \\
Content (\%) (7 d) & $0.33 \pm 0.007$ \\
Content (\%) (30 d) & $0.33 \pm 0.005$ \\
Content (\%) (90 d) & $0.33 \pm 0.004$ \\
Content (\%) (210 d) & $0.32 \pm 0.005$ \\
Size (nm) & $18.84 \pm 0.13$ \\
PDI & $0.08 \pm 0.02$ \\
\hline
\end{tabular}

${ }^{\mathrm{a}}$ Mean \pm standard deviation of $\mathrm{n}=6$ measurements

because the higher the viscosity, the greater difficulty of application in the affected area. Moreover, NE presented pseudoplastic behavior in the range 0.01 at $300 \mathrm{~s}^{-1}$; indicating that the viscosity was influenced by pressure (Figure 4A).

NE exhibited reduction in the viscosity in time function, thus the system presents thixotropic behavior, when measured at shear rate of 10 or $100 \mathrm{~s}^{-1}$ (Figure 4B) by $20 \mathrm{~min}$. This result corroborates with the pseudoplastic behavior determined in the continuous shear study (Figure 4A).

\section{In vivo study of primary skin irritation by modified Draize method}

The primary cutaneous irritation index obtained for $\mathrm{NE}$ was 0.75 . It was assessed as an average value based on edema and erythema formation in 24 and 72 hours. The reactions were graded according to the specific score described by Draize, Geoffrey, Herbert (1944) to evaluate the sensitization potential and the formulation was considered non-irritant.

\section{Characterization of the cream}

A commercial formulation (classical cream) was used for comparative purposes with the nanoemulsion. This work aims at the development of a nanoemulsion 

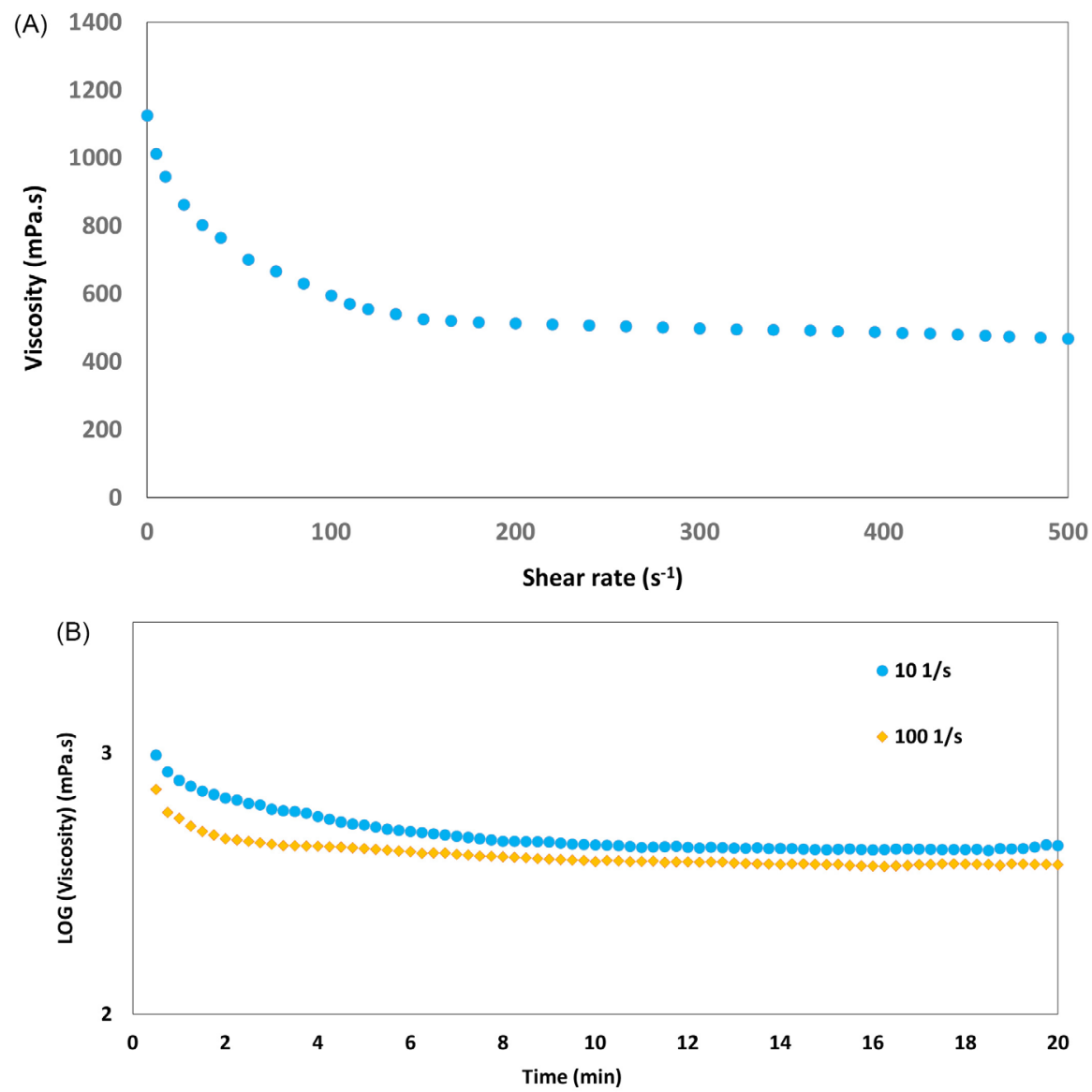

FIGURE 4 - Viscosity versus shear rate in the range from 0.01 to $500 \mathrm{~s}^{-1}$ (A) and thixotropic study using strain of 10 and $100 \mathrm{~s}^{-1}$ over a period of $20 \mathrm{~min}(\mathrm{~B})$.

with better cutaneous retention of the drug than the classical formulation. Figure 5 presents the image of the cream obtained by optical microscopy. The droplets are spherical and have micrometric size, without the presence of agglomerations and crystals. The mean diameter was $35.75 \pm 1.18 \mu \mathrm{m}$. Hence, it can be concluded that the droplets had micrometric size. The $\mathrm{pH}$ of the cream, $5.7 \pm 0.22$, is in agreement with the physiological $\mathrm{pH}$ of human skin (5.0 to 6.0) preventing allergic reactions (Segger et al., 2008).

\section{HPLC}

The typical chromatogram obtained from analysis of nifedipine is shown in Figure 6. The retention time for the nifedipine was 4.3 minutes.

The results of the validation of the analytical method are described in Table V, VI and VII. The analytic curve was linear from 2.5 to $50 \mu \mathrm{g} / \mathrm{mL}$ with correlation coefficient superior to 0.999 (Table V). Thus, the correlation coefficient value obtained from analysis of nifedipine by HPLC-UV method developed obeys the established limits (ANVISA, 2003).
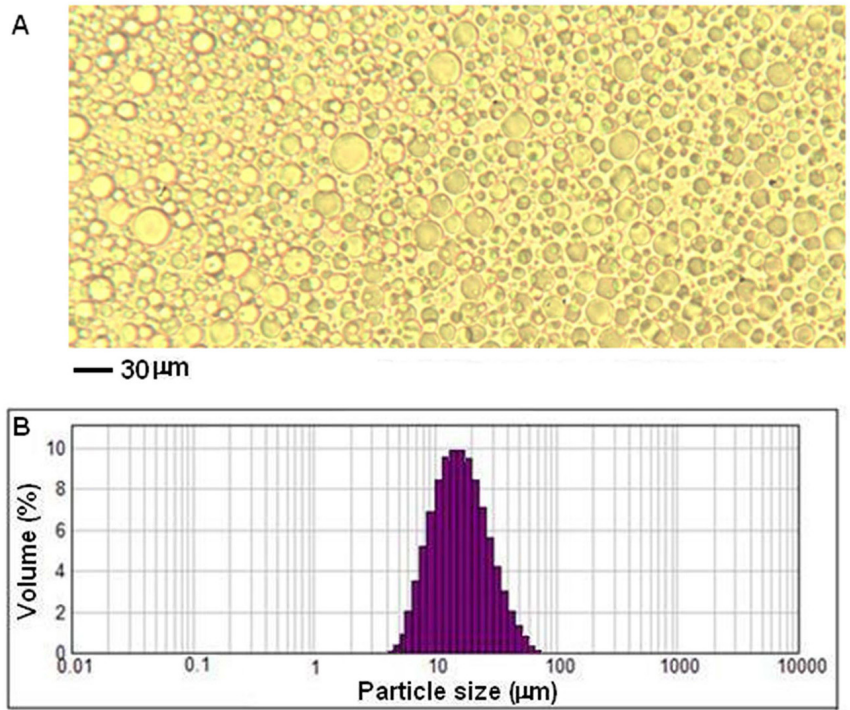

FIGURE 5 - Image of the cream obtained by optical microscopy (A) and droplet size distribution profile (B).

The method was selective because no interfering peak was detected from the skin and formulations (nanoemulsion 


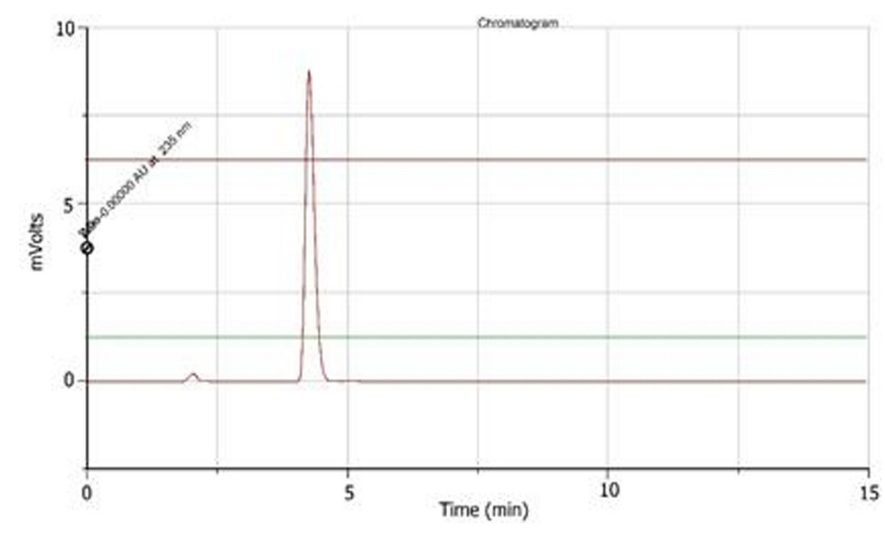

FIGURE 6 - Chromatogram of the nifedipine solution at $10 \mu \mathrm{g} /$ $\mathrm{mL}$ obtained by HPLC using Sigma-Aldrich Kromasil® ${ }^{\circledR}$ C18 column (dimensions 250 x $4.6 \mathrm{~mm} ; 5 \mu \mathrm{m}$ ), mobile phase of acetonitrile:methanol:water in 35:35:30 proportion, flow of 1.5 $\mathrm{mL} / \mathrm{min}$, ultraviolet detector (UV) with detection wavelength ( $\lambda$ ) of $235 \mathrm{~nm}$, temperature of $40{ }^{\circ} \mathrm{C}$.

TABLE V - Linear regression results and limit of quantification and limit of detection

\begin{tabular}{lc}
\hline Parameter & Value \\
\hline Concentration range & $2.5-50 \mu \mathrm{g} / \mathrm{mL}$ \\
Correlation coefficient $\left(\mathrm{R}^{2}\right)$ & 0.9999 \\
& 0.9995 \\
& 0.9999 \\
Straight-line equation & $\mathrm{y}=11950 \mathrm{x}+1269.9$ \\
& $\mathrm{y}=11753 \mathrm{x}+3053.1$ \\
& $\mathrm{y}=11677 \mathrm{x}+3698.6$ \\
\hline
\end{tabular}

and cream). The selectivity of the method is a guarantee that interfering substances of the skin and formulation do not interfere with the quantification of the nifedipine.

The precision of the method was determined by repeatability (intra-day) determined by Relative Standard
Deviation (RSD) (Table VI). Tree solutions of nifedipine in the concentrations of 5,10 and $20 \mu \mathrm{g} / \mathrm{mL}$ were analyzed on the same day under the same experimental conditions. For the determination of inter-day precision, analyzes were performed using three concentrations $(5,10$ and $20 \mu \mathrm{g} / \mathrm{mL}$ ), analyzed on two consecutive days. Table VI exhibits the results of the intra and inter-day precision. The intra-day and inter-day precision showed RSD values lower than 5\% and these values were lower than the values recommended in the literature (ANVISA, 2003).

The accuracy based in the recovery method was carried out in triplicate for three concentration levels and the results are exhibited in Table VII. The extraction method of the nifedipine from skin samples exhibited values in the range 97.6 to $102.4 \%$. The accuracy based in the recovery method showed RSD values lower than $5 \%$.

\section{In vitro permeation studies}

Nifedipine was not detected in the receptor solution of the permeation studies at 1,2 and $3 \mathrm{~h}$. However, it was detected in the receptor medium at $4 \mathrm{~h}$ in concentrations below the quantification limit (see section $H P L C$ ). Therefore, we investigated the nifedipine retention in the skin layers separately. The nanoemulsion was designed to topical administration aiming local vasodilator action. The blood vessels of the skin are located in the dermis. Therefore, we separated the two layers (epidermis/dermis) to measure the drug quantities retained in the dermis. In the experiments, we also measured the amount of drug retained in the epidermis. Figure 7 presents the drug quantities retained in the epidermis or dermis from the nanoemulsion and cream after $4 \mathrm{~h}$ of in vitro permeation study.

The in vitro permeation study is important because it provides answers to two relevant questions: whether the drug permeates to the receptor solution and the quantity of the drug retained in the skin layers.

TABLE VI - Intra-day and inter-day precision

\section{Concentration $\mu \mathrm{g} / \mathrm{mL}$}

\begin{tabular}{|c|c|c|c|c|c|c|}
\hline \multirow{3}{*}{ Precision } & \multicolumn{6}{|c|}{ Concentration $\mu \mathrm{g} / \mathrm{mL}$} \\
\hline & \multicolumn{2}{|c|}{5} & \multicolumn{2}{|c|}{10} & \multicolumn{2}{|c|}{20} \\
\hline & M & SD & M & SD & M & SD \\
\hline & RSD & & RSD & & RSD & \\
\hline \multirow[t]{2}{*}{ Intra-day * (\%) } & 61708 & 787 & 123933 & 1428 & 237713 & 2759 \\
\hline & 1.28 & & 1.15 & & 1.16 & \\
\hline \multirow[t]{2}{*}{ Inter-day** (\%) } & 61031 & 1045 & 123259 & 1540 & 2367403446 & \\
\hline & 1.71 & & 1.25 & & 1.45 & \\
\hline
\end{tabular}

* RSD of $n=6$ determinations; ** RSD of $=12$ determinations; Intra-day and intra-day precision was determined from the Relative Standard Deviation (RSD) in percentage (\%) (Anvisa, 2003); M-mean area; SD-standard deviation. 
TABLE VII - Results of the accuracy based in the extraction method of the nifedipine from skin samples

\begin{tabular}{cccc}
\hline $\begin{array}{c}\text { Added Concentrations } \\
(\boldsymbol{\mu} \mathbf{g} / \mathbf{m L})\end{array}$ & $\begin{array}{c}\text { Found Concentration** } \\
(\boldsymbol{\mu g} / \mathbf{m L})\end{array}$ & Recovery $(\mathbf{\%}) *$ & RSD $(\%)$ \\
\hline 5 & $5.12 \pm 0.11$ & 102.4 & 2.4 \\
10 & $10.17 \pm 0.07$ & 101.7 & 1.7 \\
20 & $19.79 \pm 0.11$ & 98.9 & -1.1 \\
\hline
\end{tabular}

*Mean \pm SD of $n=3$ determinations, $* *$ Mean of $n=3$ determinations, Relative Standard Deviation (RSD) in percentage $(\%)$

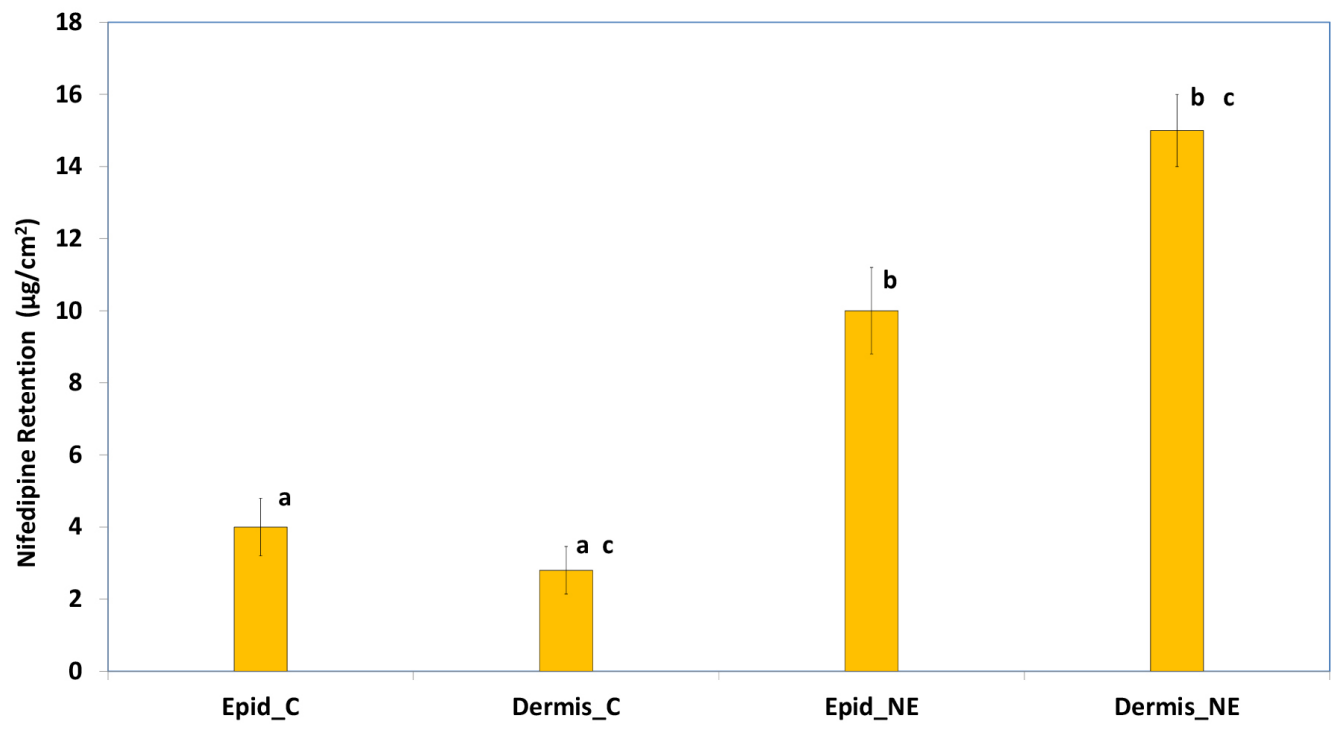

FIGURE 7 - Quantity of nifedipine retained in the epidermis or dermis after 4 hours of contact of the nanoemulsions with the skin. (a) None-statistically significant difference $(p>0.05)$ between the drug quantity retained in the epidermis in relation to the dermis; (b) Statistically significant difference $(p<0.05)$ between the drug quantity retained in the epidermis; (c) Statistically significant difference $(p<0.05)$ between the drug quantity retained in the dermis. All the results are mean \pm standard deviation of 6 measurements. $\mathrm{C}$ - Cream; NE - Nanoemulsion.

Nifedipine was detected in the receptor solution at $4 \mathrm{~h}$ in concentrations below the limit of quantification. This result is positive because it is desirable cutaneous retention of nifedipine but low permeation of the drug to the receptor solution. Figure 7 shows the drug quantities retained in the epidermis or dermis after $4 \mathrm{~h}$ of contact of the nanoemulsion with the skin. The drug quantity retained in the epidermis was higher than that retained in the dermis for the cream; however, the difference was not significant ( $p$ $>0.05)$. Analyzing the drug retention results in the dermis which is the site of action of nifedipine; nanoemulsion provided greater retention of the drug in the dermis than the cream and the mean values are statistically different $(p<0.05)$ (Figure 7). The nifedipine retention in the dermis promoted by the NE is beneficial because the vasodilator action of the drug occurs in the blood vessels located in the dermis. Bioaccumulation of nifedipine in this layer can thus promote vasodilation and accelerate wounds healing of patients with peripheral vascular disease.
Penetration of nifedipine through the stratum corneum and epidermis is necessary for bioaccumulation in the dermis. The promoting effect of cutaneous penetration of the NE can be explained by the nanometric size of the droplets $(20 \mathrm{~nm})$ with greater surface that promotes the contact of the formulation with the skin and thus improving in drug cutaneous penetration. However, the cream presents droplets with size of $35.75 \mu \mathrm{m}$, which substantially reduces the exposure area of the formulation to the skin and consequently the drug cutaneous retention.

The enhancing effect of the cutaneous penetration of the nanoemulsions has been investigated for other drugs. Nanoemulsions containing the antifungal nystatin for topical administration were prepared with the aim of promoting cutaneous penetration, preventing systemic absorption and adverse side effects (Fernandez et al., 2013). The permeation studies showed that nystatin did not pass to the receptor solution of the diffusion cell and the quantity of nystatin retained in the skin was sufficient to 
maintain the antifungal effect. Nam et al. (2012) assessed the penetration promoting effect of the nanoemulsions for tocopheryl acetate (Nam et al., 2012). The nanoemulsions promoted better skin retention of the antioxidant (Nam et al., 2012). Primo et al. (2007) formulated two nanoemulsions containing a photosensitizer for topical administration in photodynamic therapy of skin cancer and other diseases. The nanoemulsions promoted the penetration and retention of the photosensitizer in the epidermis and dermis. The formulation called "magnetic nanoemulsion" promoted photosensitizer retention in the epidermis and dermis in a higher quantity than in the stratum corneum (Primo et al., 2007).

\section{CONCLUSIONS}

The high-energy method using ultrasound was efficient to produce the nanoemulsion because it presented nanometric droplet size and low polydispersity index value. NE presented $\mathrm{pH}$ compatible with the physiological $\mathrm{pH}$ of the skin preventing irritations, as well as average droplet size of $20 \mathrm{~nm}$ and adequate polydispersity index. The formulation remained stable for seven months with excellent homogeneity.

NE presented nanometric droplets with large surface area promoting drug retention in the dermis, which is the action site of the nifedipine. Moreover, NE promoted retention of the nifedipine in the skin with small permeation of the drug to receptor solution that it is desirable for formulations administered topically.

The primary irritation tests did not show any alteration in the skin of the rabbits, so we can conclude that the formulation was not irritating.

The nanoemulsion prepared in this work is a promising drug release system to promote cutaneous retention of nifedipine and can be used in clinical trials to promote healing of wounds caused by circulatory problems.

\section{ACKNOWLEDGEMENTS}

We thank the Office to Improve University Research (CAPES), National Scientific and Technological Research Council (CNPQ) for financial support.

\section{REFERENCES}

AGÊNCIA NACIONAL DE VIGILÂNCIA SANITÁRIA. ANVISA. RE n. 899, de 29/05/2003. Guia para validação de métodos analíticos e bioanalíticos. Ministério da Saúde: Brasil, 2003.
ALI, S.L. Nifedipine. In: FLOREY, K. (Ed.). Analytical profiles of drug substances. New York: Academic Press, 1989. v.18, p.221-288.

CALABRO, G.; DE VITA, V.; PATALANO, A.; MAZZELLA, C.; LO CONTE, V.; ANTROPOLI, C. Confirmed efficacy of topical nifedipine in the treatment of facial wrinkles. $J$. Dermatolog. Treat., v.25, n.4, p.319-325, 2014.

CAMPOS, V.E.B.; RICCI-JÚNIOR, E.; MANSUR, C.R.E. Nanoemulsions as delivery systems for lipophilic drugs. $J$. Nanosci. Nanotechno., v.11, n.3, p.2881-2890, 2012.

EBADI, A.; CHERAGHALI, A.M.; QOSHONI, H.; EIMANI, H. Healing effect of topical nifedipine on skin wounds of diabetic rats. DARU, v.11, n.1, p.1-4, 2003.

DRAIZE, J.H.; GEOFFREY, W.; HERBERT, O.C. Methods for the study of irritation and toxicity of substances applied topically to the skin and mucous membranes. $J$. Pharmacology Exp. Ther., v.83, p.377-390, 1944.

FERNANDEZ, C.F.; CLARES, N.B.; LOPEZ, S.O.; ALONSO, M.C.; CALPENA, A.C.A. Evaluation of novel nystatin nanoemulsion for skin candidosis infections. Mycoses, v.56, n.1, p.70-81, 2013.

GAD, S.C.; MCCORD, M.G. Local tissue tolerance. In: . Safety evaluation in the development of medical devices and combination products. 3.ed. Florida: CRC Press; Taylor and Francis Group, 2008. p.83-96.

GOLFAM, F.; GOLFAM, P.; KHALAJ, A.; SAYED, M.S. The effect of topical nifedipine in treatment of chronic anal fissure. Acta Med. Iran., v.48, n.5, p.295-299, 2010.

HERBAL MEDICINE. Expanded Commission Online. Peppermint oil monograph. Published by the American Botanical Council. 2000. Available at: http://cms. herbalgram.org/expandedE/Peppermintoil.html. Accessed on: April 04, 2015.

INNOCENTI, M.; RAMONI, S.; DORIA, C.; ANTROPOLI, C.; GARBAGNA, N.; GROSSI, E.; VERALDI, S. Treatment of periocular wrinkles with topical nifedipine. J. Dermatolog. Treat., v.21, n.5, p.282-285, 2010. 
KATSINELOS, P.; PAPAZIOGAS, B.; KOUTELIDAKIS, I.; PAROUTOGLOU G.; DIMIROPOULOS, S.; SOUPARIS, A.; ATMATZIDIS. K. Topical 0.5\% nifedipine vs. lateral internal sphincterotomy for the treatment of chronic anal fissure: long-term follow-up. Int. J. Colorectal Dis., v.21, n.2, p.179-183, 2006.

KONG, M.; CHEN, X.G.; KWEON, D.K.; PARK, H.J. Investigations on skin permeation hyaluronic acid based nanoemulsions as transdermal carrier. Carbohyd. Polym., v.86, n.2, p.837-843, 2011.

MELO, P.G.; PEDROSO, M.C.; FELICE, T. D.; MENDES, R.C.D.; SCHMITZ, W. O efeito do gel de Nifedipina no tratamento de úlceras de pressão. Lat. Am. J. Pharm., v.27, n.3, p.410-414, 2008.

MONTEIRO, M.S.S.B.; OZZETTI, R.A.; VERGNANINI, A.L.; GITIRANA, L.B.; VOLPATO, N.M.; FREITAS, Z.M.F.; RICCI-JÚNIOR, E.; SANTOS, E.P. Evaluation of octyl p-methoxycinnamate included in liposomes and cyclodextrins in anti-solar preparations: preparations, characterizations and in vitro penetration studies. Int. $J$. Nanomed., v.7, p.3045-3058, 2012.

NAM, Y.S.; KIM, J.W.; PARK, J.; SHIM, J.; LEE, J.S.; HAN, S.H. Tocopheryl acetate nanoemulsions stabilized with lipid-polymer hybrid emulsifiers for effective skin delivery. Colloid Surf. B., v.94, p.51-57, 2012.

NEUBERT, H.R. Potentials of new nanocarriers for dermal and transdermal drug delivery. Eur. J. Pharm. Biopharm., v.77, n.1, p.1-2, 2011.

PRIMO F.L.; MICHIELETO, L.; RODRIGUES, M.A.M.; MACAROFF, P.P.; MORAIS, P.C.; LACAVA, Z.G.M.; BENTLEY, M.V.L.B.; TEDESCO, A.C. Magnetic nanoemulsions as drug delivery system for Foscan ${ }^{\circledR}$ : skin permeation and retention in vitro assays for topical application in photodynamic therapy (PDT) of skin cancer. J. Mag. Mag. Mater., v.311, p.354-357, 2007.
SCHAEFER, H.; REDELMEIER, T.E. Skin barrier: principles of percutaneous absorption. Basel, Switzerland: S. Karger AG, 1996. p.1-310

SEGGER, D.; RHEINLÄNDER, T.; SCHMIDTLEWERKÜHNE, H.; SCHNEIDER, W. Multicenter study on measurement of the natural $\mathrm{pH}$ of the skin surface. Int. J. Cosmet. Sci., v.30, n.1, p.75-80, 2008.

SENNA, J.P.; RICCI-JÚNIOR, E.; MANSUR, C.R.E. Development and evaluation of nanoemulsions containing phthalocyanines for use in photodynamic cancer therapy. J. Nanosci.. Nanotechnol., v.15, n.6, p.4205-4214, 2015.

SMITH, R.G. Off-label use of prescription medication: a literature review. Wounds, v.22, n.4, p.78-86, 2010.

TORSIELLO, M.J.; KOPACKI, M.H. Transdermal nifedipine for wound healing: case reports. Int. J. Pharm. Compd., v.4, n.5, p.356-358, 2000.

TROMMER, H.; NEUBERT, H.R. Overcoming the stratum corneum: the modulation of skin penetration: a review. Skin Pharmacol. Physiol., v.19, n.2, p.106-121, 2006.

WILLIAMS, A. Transdermal and topical drug delivery: from theory to clinical practice. Pharmaceutical Press: London, 2003. p.54-58.

ZETASIZER NANO. User manual: Man0485, n.1.1. Malvern: Malvern Instruments, 2004.

Received for publication on $21^{\text {st }}$ December 2015 Accepted for publication on $19^{\text {th }}$ December 2016 